\title{
The Role of School Connectedness and Family Cohesion in Predicting Bullying and Victimization in an Iranian Sample
}

\section{Soghra Ebrahimi Ghavam ${ }^{1}$ and Hasan Khezri ${ }^{2 *}$}

1. Department of Educational Psychology, Allameh Tabatabaei University, Tehran, Iran

2. Department of Psychology, Islamic Azad University, Firouzabad Branch, Firouzabad, Iran.

*Corresponded author Email: hasan_khezri@yahoo.com; 00989173044563

\begin{abstract}
The aim of this research was to predicting bullying and victimization in school students (boys \& girls) in Shiraz, in accordance to the school connectedness and the family cohesion. For this purpose, 564 students from middle schools were selected by cluster random sampling and they completed Illinois Bullying Scale, Family Adaptability and Cohesion Evaluation Scale (FACES II), and Student Perceptions of School Connectedness scale. Analysis was performed using SPSS16 software showed that the school connectedness with the standard beta coefficient -0.372 , $\mathrm{t}=-9.28$ at the $99 \%$ confidence level $(\mathrm{p}<0.01)$ and family cohesion, with standardized beta coefficient $-0.184, \mathrm{t}=-4.59$ at the $99 \%$ confidence level $(\mathrm{p}<0.01)$ predicted $22 \%$ of the variance of bullying. Also, was found that the school connectedness with the standard beta coefficient $0.310, \mathrm{t}=-7.313$ at the $99 \%$ confidence level $(\mathrm{p}<0.01)$ and family cohesion, with standardized beta coefficient $-0.090, \mathrm{t}=-2.115$ at the $99 \%$ confidence level $(\mathrm{p}<0.01)$ predicted $13 \%$ of the variance of victimization. In general, findings indicate that the weakness of family cohesion and school connectedness can be fertile ground for violent behavior at school (bullying and being victimized) by the students.
\end{abstract}

Keywords: Middle school students, Bullying, Victimization, Family Cohesion, School Connectedness.

\section{Introduction}

Bullying is a set of physical and/or verbal behaviors that a person or a group of persons, directs against a peer, in a hostile, repetitive and continuous manner, by using real or unreal power with intend cause to harm the victim (Benitez Muñoz \& Justicia Justicia, 2006). Researchers in the field of school violence have always sought to identify important factors influencing this phenomenon and its consequences; so in the light of the knowledge gained from the research findings, deal effectively with this harmful phenomenon. Previous studies have shown that bullying is a multifaceted phenomenon, which arises from the interweaving of family relationships, peer relations, school community and culture (Swearer \& Doll, 2001).

One of the family factors influencing the growth and health of children is family cohesion. When we talked about family cohesion, in fact, it refers to a situation in which the family members are close to each other and have an emotional bond, as well as a refers to a high degree of warmth, togetherness, harmony and physical intimacy (Green \& Werner, 1996). It is known that students without family support are more likely to engage in violence common among peers (Laufer \& Harel, 2003).

Wienke Totura et al. (2009)have shown that compared to other students, bullies, have reported the lowest rate of family cohesion. In Murray-Harvey \& Slee research (2010) has shown 
that family cohesion has a direct and indirect effect on bullying and victimization. Also, in a meta-analysis was conducted by Espelage and Swearer (Espelage \& Swearer, 2003) about bullying and victimization in schools, they found that existing research literature on aggression and domestic factors have provided valuable support that illustrates the relationship between aggressive behavior in adolescents and the lack of family cohesion, inadequate parental supervision, violence in the family, violent disciplinary practices, and lack of benchmarking problem-solving skills; in addition, there are high levels of conflict in the family and problematic behaviors such as drug abuse among parents of aggressive children. Espelage \& Swearer (2003) have shown in their meta-analysis that the families of the victims are more cohesive than bullies' family; however, a mother with excessive support may be in the victims' families.

On the other hand, students spent the major part of their lifetime in school, and thus, school experiences doesn't only shaped the lives of students in the school but also could change the life of students after school (Murray-Harvey \& Slee, 2010).

The impact of school on academic and social growth of students and in particular, educational achievement acts through the structure, staff, organization, resources, and school climate (Stewart, 2008). In other words, the school environment should establish a link between students, teachers, and the school (Backus, 2010) to grow the academic, emotional, behavioral, and relationships with others (Wilson, 2004).

School connectedness can be defined as:

a. To care for others in the school and respect each other's opinions and expectations;

b. Giving value to educational goals;

c. Participating in school related activities and;

d. To accept the school rules as fair rules and adhere to them (Jenkins, 1997).

Researchers (e.g. (Springer, McQueen, Quintanilla, Arrivillaga, \& Ross, 2009; Wienke Totura et al., 2009); have shown that School connectedness, is an important factor in reducing the likelihood of engaging students in harmful behaviors and adolescents in such educational settings are less likely to engage in behaviors such as bullying, escape from school, contributing in fight, and hooliganism.

In general, it can be said that short-term and long-term negative effects of bullying phenomenon, in terms of individual, social and educational aspects studied and verified in many western samples (Swearer, Espelage, Vaillancourt, \& Hymel, 2010). Now is the time that bullying, examine in the eastern samples, especially in Middle East communities in order to recognize and stop it. Because bullying should not be regarded as a natural period of child development; rather it should be seen as a prelude to more violent and serious behaviors, which need necessarily immediate intervention and proper care of adults (Piotrowski \& Hoot, 2008). The importance of those findings in other populations on one hand, and the lack of studies on the factors in bullying, in the context of Iranian education, in other hand has been the main impetus for this study. For this reason, we attempt to study the relationships between family cohesion and school connectedness with bullying and victimization in a sample of middle school students in Iran. 


\section{Material and Methods}

Participants: The study population included all boys and girls students in the second and third classes of the four educational districts of Shiraz. Sampling method in this study was randomized cluster sampling. This means that at first from a list of schools in the four educational districts in Shiraz accident, were selected 10 schools (5 boys and 5 girls' schools) and then from each school, two classes (totally 20 classrooms at the second and third grades) were selected and questionnaires and scales were administered in each class. In total, 564 students (287 boys and 277 girls) were selected.

\section{Tools}

Illinois bullying scale: This is an 18-item instrument that covers various aspects of the phenomenon of bullying (bullying and victimization). At this scale, the respondents are asked to show that during the past month, how much bullying behavior had attempt and also to what extent were bullied. They should specify their answers on a 5-point Likert scale (from never $=0$; 1 to two times per month $=1 ; 3$ to 4 times per month $=2 ; 5$ to 6 times per month $=3$; and 7 times and more $=4$ ). The total score for each subject in each subscale (bullying and victimization), can be obtained by adding up the scores of specified items. Thus, the range of scores for victimization subscale is from 0 to 16 (4 items); the higher scores indicate more victimization. On the other hand, the range of bullying scores is variable from 0 to 36 ( 9 items), which means to increase the score the more severe bullying. Espelage and Holt (2001) reported sufficient Cronbach's alpha coefficients for the bullying (0.87), and victimization (0.88) subscales.

Student Perceptions of School Cohesion (SPSC) scale: is a 10-item scale that asks students to rate with a 5-point Likert-type response scale their perceptions of the school social environment.

This tool has three subscales: school supportive relationships, Student-school connectedness and teacher-student connectedness. The minimum score on supportive school relationships and student-school connectedness subscales is 4 and the maximum score is 20 .

Family Adaptability and Cohesion Scale: is a 30-item instrument that used to measure the cohesion, support, relationships and family atmosphere. This tool has the following scale:

a. Adaptability, which represents the ability to adapt during the trials of family stress

b. Cohesion, which shows the bond and individuality within a family system.

Cohesion subscale has 16 items and adaptability subscale consists of 14 items.

The subjects were asked to respond on a 5-point Likert scale from $1=$ never and always $=$ 5. Olson, Bell and Portner (1992)have reported for the cohesion subscale, Cronbach's alpha coefficient 0.87 and Cronbach's alpha coefficient 0.78 for adaptability and for the total subscale, Cronbach's alpha coefficient 0.90 .

\section{Results}

As you can see in tables 1 and 2, there are descriptive indicators as well as the correlation matrix of the variables. In order to test the first question of the study, we used enter method of multiple regression. The results showed that family cohesion and school connectedness can predict bullying. Thus, as shown in table 3,4, and 5, the predictive variables (family cohesion and school connectedness) explained $22 \%$ of bullying variance. 
Table 1.Mean, standard deviation and correlation coefficients of bullying, school connectedness, and family cohesion $(\mathrm{n}=564)$

\begin{tabular}{|c|c|c|c|c|c|}
\hline Variable & Mean & SD & Variable 1 & Variable 2 & Variable 3 \\
\hline 1-bullying & 5.65 & 6.38 & ------ & ----- & ----- \\
\hline 2-school connectedness & 27.39 & 9.52 & -0.44 & ----- & ----- \\
\hline 3-family cohesion & 90.03 & 18.21 & -0.32 & +0.37 & ------- \\
\hline
\end{tabular}

Table 2. Mean, standard deviation and correlation coefficients of victimization, school connectedness, and family

\begin{tabular}{|c|c|c|c|c|c|}
\hline \multicolumn{7}{|c|}{ cohesion $(\mathrm{n}=564)$} \\
\hline Variable & Mean & SD & Variable 1 & Variable 2 & Variable 3 \\
\hline 1-victimization & 4.18 & & ------ & ------ & ----- \\
\hline 2-school connectedness & 27.39 & 9.52 & -0.34 & ----- & ----- \\
\hline 3-family cohesion & 90.03 & 18.21 & -0.20 & +0.37 & ------- \\
\hline
\end{tabular}

Table 3.Summary of prediction model of bullying based on family cohesion and school connectedness

\begin{tabular}{|c|c|c|c|c|}
\hline Model & $\mathrm{R}$ & $R^{2}$ & Adjusted $R^{2}$ & Standard Error of Estimate \\
\hline 1 & 0.471 & 0.222 & 0.219 & 5.63 \\
\hline
\end{tabular}

*Predictor variables: family cohesion, school connectedness.

Table 4. Results of regression analysis to predict bullying based on family cohesion and school connectedness

\begin{tabular}{|c|c|c|c|c|c|c|}
\hline Model & & Mean of squares & df & Sum of Squares & F & Significance Level \\
\hline \multirow{3}{*}{1} & Regression & 5066.22 & 2 & 2533.11 & 79.98 & 0.000 \\
\cline { 2 - 7 } & Residual & 1776.66 & 561 & 31.67 & & \\
\cline { 2 - 7 } & Total & 22833.88 & 563 & & & \\
\hline
\end{tabular}

* Predictor variables: family cohesion, school connectedness

Table 5. Beta coefficients and t tests for predictor variables

\begin{tabular}{|c|c|c|c|c|c|c|}
\hline Model & Variable & \multicolumn{2}{|c|}{ Non-standard } & coefficients & Standard \\
coefficients & & \\
\hline \multirow{3}{*}{1} & & $\mathrm{~B}$ & Standard Error & $\beta$ & $\mathrm{t}$ & $\mathrm{P}$ \\
\cline { 2 - 7 } & & 18.24 & 1.226 & & 14.88 & 0.000 \\
\cline { 2 - 7 } & Constant & -0.248 & 0.027 & -0.372 & -9.28 & 0.000 \\
\cline { 2 - 7 } & School connectedness & -0.064 & 0.014 & -0.184 & -4.59 & 0.000 \\
\hline
\end{tabular}

* Predictor variables: family cohesion, school connectedness

In order to answer the second question test, we made use of the enter method of multiple regression. The results also showed that family cohesion and school connectedness can predict victimization. Thus, according to Tables 6, 7, and 8, the predictor variables (family cohesion and school connectedness) explained $13 \%$ of the victimization's variance.

Table 6. Summary of prediction model of victimization based on family cohesion and school connectedness

\begin{tabular}{|l|l|l|l|l|}
\hline Model & $\mathrm{R}$ & $R^{2}$ & Adjusted $R^{2}$ & Standard Error of Estimate \\
\hline 1 & 0.353 & 0.125 & 0.122 & 3.875 \\
\hline
\end{tabular}

* Predictor variables: family cohesion, school connectedness. 
Table 7. Results of regression analysis to predict victimization based on family cohesion and school connectedness

\begin{tabular}{|l|l|l|l|l|l|l|}
\hline Model & & Mean of squares & df & Sum of Squares & F & Significance Level \\
\hline \multirow{4}{*}{1} & Regression & 1201.92 & 2 & 600.96 & 40.02 & 0.000 \\
\cline { 2 - 8 } & Residual & 8424.99 & 561 & 15.02 & & \\
\cline { 2 - 8 } & Total & 9626.91 & 563 & & & \\
\hline
\end{tabular}

* Predictor variables: family cohesion, school connectedness

Table 8. Beta coefficients and t tests for predictor variables

\begin{tabular}{|l|l|l|l|l|l|l|}
\hline \multirow{2}{*}{ Model } & Variable & \multicolumn{2}{|l|}{ Non-standard coefficients } & $\begin{array}{l}\text { Standard } \\
\text { coefficients }\end{array}$ & & \\
\hline \multirow{3}{*}{1} & & $\mathrm{~B}$ & Standard Error & $\mathrm{B}$ & $\mathrm{t}$ & Significance Level \\
\cline { 2 - 7 } & Constant & 9.71 & 0.844 & & 11.495 & 0.000 \\
\cline { 2 - 7 } & School connectedness & -0.135 & 0.018 & -.031 & -7.313 & 0.000 \\
\cline { 2 - 7 } & Family cohesion & -0.020 & 0.010 & -0.09 & -2.115 & 0.000 \\
\hline
\end{tabular}

* Predictor variables: family cohesion, school connectedness

\section{Discussion}

This study was carried out to predict bullying and victimization based on family cohesion and school connectedness in a sample consisting of middle school students. According to the results of school connectedness, in a negative way, explained victimization and bullying. To explain these findings, we can say that school connectedness, including the attachment to the people in the school and a sense of belonging to the school and being a part of it. In this regard, Catalano, Oesterle, Fleming and Hawkins (2004) have defined school connectedness by two interconnected components:

a. Attachment that identifies by emotional and close relationship with other people in the school; and

b. Commitment which can be determined by spending time and good behavior at school.

Thus, it is clear that school connectedness can act as a protective factor for violent behaviors and law-defying actions. In addition, in this study, school connectedness was based on three components: school supportive relationships, Student-school connectedness, and teacherstudent connectedness. It is obvious that "a supportive environment at school and having bond with school has protective effects against engaging in risky behavior" (Springer et al., 2009; Sprott, Jenkins, \& Doob, 2005). On the other hand, student-teacher connectedness and studentschool connectedness also cover supporting students by teacher, helping students in the face of troubles, positive bilateral relationship, the feeling of being loved by the teacher, paying attention to students' comments by teachers, and hear the views of students by school staff (Libbey, 2004). These items provide a positive atmosphere in the school that can improve students' attitude to school and can reduce students' engaging in violence and reduce the number of victims of these behaviors (Moos, 2003). 


\section{References}

Backus, A. S. (2010). The relationship between bullying behaviors and perceived school connectedness among middle school students. Kent State University.

Benitez Muñoz, J. L., \& Justicia Justicia, F. (2006). Bullying: description and analysis of the phenomenon.

Catalano, R. F., Oesterle, S., Fleming, C. B., \& Hawkins, J. D. (2004). The importance of bonding to school for healthy development: Findings from the Social Development Research Group. Journal of school health, 74(7), 252-261.

Espelage, D. L., \& Holt, M. K. (2001). Bullying and victimization during early adolescence: Peer influences and psychosocial correlates. Journal of Emotional Abuse, 2(2-3), 123-142.

Espelage, D. L., \& Swearer, S. M. (2003). Research on school bullying and victimization: What have we learned and where do we go from here? School psychology review, 32(3), 365384.

Green, R. J., \& Werner, P. D. (1996). Intrusiveness and closeness-caregiving: Rethinking the concept of family "enmeshment". Family process, 35(2), 115-136.

Jenkins, P. H. (1997). School delinquency and the school social bond. Journal of research in crime and delinquency, 34(3), 337-367.

Laufer, A., \& Harel, Y. (2003). The role of family, peers and school perceptions in predicting involvement in youth violence. International journal of adolescent medicine and health, $15(3), 235-244$.

Libbey, H. P. (2004). Measuring student relationships to school: Attachment, bonding, connectedness, and engagement. Journal of school health, 74(7), 274-283.

Moos, R. H. (2003). Social contexts: Transcending their power and their fragility. American journal of community psychology, 31(1-2), 1-13.

Murray-Harvey, R., \& Slee, P. T. (2010). School and home relationships and their impact on school bullying. School Psychology International, 31(3), 271-295.

Olson, D. H., Bell, R., \& Portner, J. (1992). Family inventories manual. Minneapolis, MN: Life Innovations.

Piotrowski, D., \& Hoot, J. (2008). Bullying and violence in schools: What teachers should know and do. Childhood Education, 84(6), 357-363.

Springer, A. E., McQueen, A., Quintanilla, G., Arrivillaga, M., \& Ross, M. W. (2009). Reliability and validity of the Student Perceptions of School Cohesion Scale in a sample of Salvadoran secondary school students. BMC international health and human rights, 9(1), 30 .

Sprott, J. B., Jenkins, J. M., \& Doob, A. N. (2005). The importance of school: Protecting at-risk youth from early offending. Youth Violence and Juvenile Justice, 3(1), 59-77.

Stewart, E. B. (2008). School structural characteristics, student effort, peer associations, and parental involvement: The influence of school-and individual-level factors on academic achievement. Education and urban society, 40(2), 179-204.

Swearer, S. M., \& Doll, B. (2001). Bullying in schools: An ecological framework. Journal of Emotional Abuse, 2(2-3), 7-23. 
Swearer, S. M., Espelage, D. L., Vaillancourt, T., \& Hymel, S. (2010). What can be done about school bullying? Linking research to educational practice. Educational researcher, 39(1), $38-47$.

Wienke Totura, C. M., MacKinnon-Lewis, C., Gesten, E. L., Gadd, R., Divine, K. P., Dunham, S., \& Kamboukos, D. (2009). Bullying and victimization among boys and girls in middle school: The influence of perceived family and school contexts. The Journal of Early Adolescence, 29(4), 571-609.

Wilson, D. (2004). The interface of school climate and school connectedness and relationships with aggression and victimization. Journal of school health, 74(7), 293-299. 